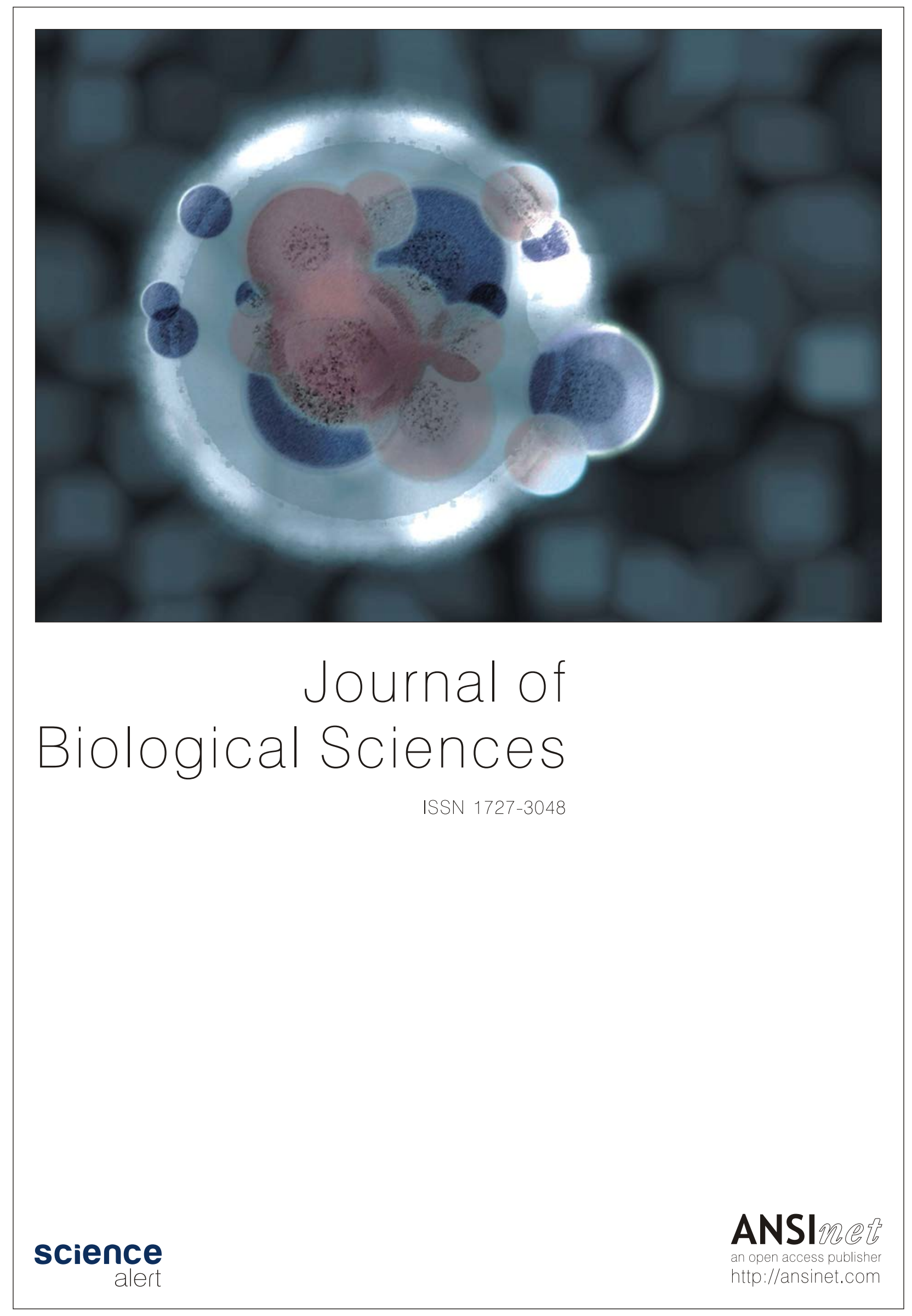




\title{
Antioxidant and Anti-diabetic Effects of Cumin Seeds Crude Ethanol Extract
}

\author{
Doha Abdou Mohamed, Ibrahim Mohamed Hamed and Karem Aly Fouda \\ Department of Nutrition and Food Sciences, National Research Centre, Dokki, Cairo, Egypt
}

\section{Abstract}

Background and Objective: Diabetes is a metabolic disease associated with hyperglycemia. Diabetes is the major cause of morbidity and mortality worldwide. Chronic hyperglycemia in diabetic patients leads to damage and dysfunction of many organs. The aim of the present research was studying the anti-diabetic potential of crude ethanol extract of cumin seeds (CEEC). Methods: CEEC was prepared. Diabetes was induced in rats by single dose of streptozotocin (STZ). Total flavonoids and total phenolic contents were determined in the CEEC. Free radical scavenging activity of the extract was estimated using DPPH method. Acute toxicity of the CEEC on mice was determined. The effect of CEEC on glucose tolerance was evaluated. Results: The results revealed that total phenolic and total flavonoids were presence in the CEEC by $23.02 \pm 0.045 \mathrm{mg} \mathrm{GAE} \mathrm{g}^{-1}$ extract and $19 \pm 0.132 \mathrm{mg} \mathrm{QE} \mathrm{g}^{-1}$ extract, respectively. CEEC showed free radical scavenging activity. Acute toxicity revealed that CEEC was completely safe up to $12 \mathrm{~g} \mathrm{~kg}^{-1}$ mice. Oral administration of CEEC reduced glycemic levels. CEEC significantly reduced plasma glucose levels in diabetic rats and elevate insulin levels significantly compared with diabetic control. CEEC improved plasma lipid profile, reduced oxidative stress and reduced inflammation in diabetic rats. Conclusion: Crude ethanol extract of cumin seeds may be used as alternative treatment for diabetes. The results indicated that CEEC may be very helpful in the improvement of plasma lipid profile as one of the risk factors for cardiovascular diseases and heart failure in diabetic patients.

Key words: Cuminum cyminum seeds, glucose tolerance, diabetic rats, acute toxicity, DPPH
Received: April 06, 2018
Accepted: May 30, 2018
Published: June 15, 2018

Citation: Doha Abdou Mohamed, Ibrahim Mohamed Hamed and Karem Aly Fouda, 2018. Antioxidant and anti-diabetic effects of cumin seeds crude ethanol extract. J. Biol. Sci., 18: 251-259.

Corresponding Author: Doha Abdou Mohamed, Department of Nutrition and Food Sciences, National Research Centre, Dokki, Cairo, Egypt

Copyright: @ 2018 Doha Abdou Mohamed et al. This is an open access article distributed under the terms of the creative commons attribution License, which permits unrestricted use, distribution and reproduction in any medium, provided the original author and source are credited.

Competing Interest: The authors have declared that no competing interest exists.

Data Availability: All relevant data are within the paper and its supporting information files. 


\section{INTRODUCTION}

Diabetes mellitus (DM) is a metabolic disease associated with hyperglycemia. Diabetes is the major cause of morbidity and mortality worldwide ${ }^{1}$. DM is estimated to affect about 366 million by 2030. Incidence of diabetes is increased dramatically, this increment not only affect the individual health but elevate the cost of health care and has implications for economic and social issues of the society ${ }^{2}$. Type II diabetes (T2D) has increased during the recent years, its affect 90-95 of diabetic patients. T2D is one of the risk factors for cardiovascular diseases ${ }^{3}$. Unlimited elevation in blood glucose levels leads to increase oxidative stress, which induce damage cell tissue and causes vital changes in the function and structure of organs ${ }^{1}$. Exogenous insulin and/oral hypoglycemic drugs can be used to control hyperglycemia in diabetic patients ${ }^{4}$. Sometimes the side effect due to interaction between medications could induce side effects more serious than the disease itself. So search for natural alternatives to control diabetes and maintain blood sugar levels is very important. These natural alternatives are safer than pharmacological drugs. There has been an increase in the use of herbal products to complement conventional drugs in the treatment of various diseases ${ }^{5}$. Herbal medicines have been proposed as suitable alternatives in the management of diabetes due to their availability and few side effects ${ }^{6}$. It was reported previously that herbs regulate blood glucose levels through different mechanisms i.e. lowering carbohydrate absorption, enhancing insulin sensitivity and peripheral glucose uptake, stimulating the secretion of insulin and endogenous incretins, preventing cell apoptosis by exerting antioxidant effects and promoting glycogenesis or inhibiting glycogenolysis ${ }^{7}$. Cumin (Cuminum cyminum L.), seeds (green cumin) is herbaceous plant belong to Apiaceae family. Cumin is indigenous to the Mediterranean region and has been popularly used as spice. Previous studies suggested that cumin possess a broad range of pharmacological activities such as antibacterial ${ }^{8}$, antioxidant ${ }^{9}$, hypoglycemic ${ }^{10}$ and anti-carcinogenic ${ }^{11}$. Cumin seeds contain $5 \%$ volatile oil, $22 \%$ fat, $10 \%$ protein and $11 \%$ fibers. The major volatile components of cumin are cuminaldehyde, cymene and terpenoids ${ }^{12}$. Transdermal nanoemulsion prepared from cumin seeds volatile oil possesses antioxidant and hepatoprotective effect in rats ${ }^{13}$. The aim of the present research was studying the anti-diabetic potential of crude ethanol extract of cumin seeds.

To achieve this goal the antioxidant activity of the CEEC, its effect on glucose tolerance and acute toxicity were evaluated. Also the content of total phenolic and total flavonoids were assessed.

\section{MATERIALS AND METHODS}

\section{Cumin (green cumin) (Cuminum cyminum L.) seeds were} purchased from local markets.

Animals: Male albino rats, of $137.9 \pm 5.959 \mathrm{~g}$ as (Mean \pm SD) were used. Animals were obtained from the animal house of National Research Centre, Cairo, Egypt. The animals were kept individually in stainless steel cages at room temperature. Water and food were given ad-libitum. Adult normal male and female albino mice of 21-25 $\mathrm{g}$ body weight were used in an acute toxicity test.

Diets: A balanced diet composed of $12.5 \%$ casein, $10 \%$ corn oil, $22.7 \%$ sucrose, $45.3 \%$ maize starch, $5 \%$ fiber, $3.5 \%$ salt mixture ${ }^{14}$ and $1 \%$ vitamin mixture ${ }^{15}$ was prepared for feeding rats all over the experimental period. One-hundred microliter of fat soluble vitamins was given orally to each rat per week.

All chemical used in the present study were analytical grade and purchased from Sigma-Aldrich.

Preparation of plant extract: The air-dried powdered of cumin seeds were extracted successively in a continuous extraction apparatus (Soxhlet) until exhaustion with ethanol for preparation of crude ethanol extract. The solvent was completely removed by evaporation under reduced pressure at a temperature not exceeding $40^{\circ} \mathrm{C}$. Crude extract of cumin were kept in deep-freeze till used.

Determination of phenolic compounds: Total phenolics were determined colorimetrically in the cumin crude ethanol extract using Folin-Ciocalteu reagent ${ }^{16}$. Absorbance was measured at $765 \mathrm{~nm}$ using UVPC spectrophotometer. The total phenolic content was expressed as gallic acid equivalents (GAE) in $\mathrm{mg} \mathrm{g}^{-1}$ extract. The results were expressed as Mean $\pm \mathrm{SE}$.

Determination of total flavonoids: Total flavonoid content of cumin extract was determined by the aluminum chloride colorimetric method ${ }^{17}$. In brief, $50 \mu \mathrm{L}$ of crude extract (1 $\mathrm{mg} \mathrm{mL}^{-1}$ ethanol) were made up to $1 \mathrm{~mL}$ with methanol, mixed with $4 \mathrm{~mL}$ of distilled water and then $0.3 \mathrm{~mL}$ of $5 \%$ $\mathrm{NaNO}_{2}$ solution; $0.3 \mathrm{~mL}$ of $10 \% \mathrm{AlCl}_{3}$ solution was added after 5 min of incubation and the mixture was allowed to stand for $6 \mathrm{~min}$. Then, $2 \mathrm{~mL}$ of $1 \mathrm{~mol} \mathrm{~L}^{-1} \mathrm{NaOH}$ solution were added and the final volume of the mixture was brought to $10 \mathrm{~mL}$ with double-distilled water. The mixture was allowed to stand for $15 \mathrm{~min}$ and absorbance was measured at $510 \mathrm{~nm}$. The total flavonoid content was calculated from a calibration curve 
and the result was expressed as $\mathrm{mg}$ quercetin equivalent per $g(\mathrm{QE})$. The results were expressed as Mean $\pm \mathrm{SE}$.

\section{In vitro antioxidant evaluation using DPPH assay: $\mathrm{DPPH}$} free radical scavenging activity was estimated in CEEC using concentrations range 200 and $1000 \mu \mathrm{g} \mathrm{mL} \mathrm{L}^{-1}$, respectively. CEEC sample was diluted using ethanol as a diluting solvent. One milliliter of the sample was added to $4 \mathrm{~mL} \mathrm{DPPH}$ solution $\left(20 \mathrm{mg} \mathrm{L}^{-1}\right)^{18}$, incubated for $60 \mathrm{~min}$ in the dark ${ }^{19}$ and afterwards, absorbance was measured spectrophotometrically at $517 \mathrm{~nm}$. Control samples were prepared using DPPH solution without any test samples. The percent DPPH scavenging activity (SC \%) was calculated as:

$$
\mathrm{SC}(\%)=\frac{\mathrm{AC}-\mathrm{AS}}{\mathrm{AC}} \times 100
$$

Where:

$A C=$ Absorbance of control sample

AS $=$ Absorbance of test sample

Preparation of dosage form: Crude ethanol extract of cumin seeds was dispersed separately in water to be given orally to rats.

Effect of crude ethanol extract and glibenclamide on oral
glucose tolerance in normal rats: Eighteen rats were divided into three groups, each comprised of six rats. All rats were fasted overnight. Glucose tolerance test in fasted rats was performed using one gram glucose $\mathrm{kg}^{-1}$ rat body weight ${ }^{20}$. Rats of group one (control) was given oral glucose solution $\left(1 \mathrm{~g} \mathrm{~kg}^{-1}\right)$. Rats of group two and three were given crude ethanol extract of cumin seeds $\left(200 \mathrm{mg} \mathrm{kg}^{-1}\right.$ ) or glibenclamide $\left(5 \mathrm{mg} \mathrm{kg}^{-1}\right)$ followed by glucose solution $\left(1 \mathrm{~g} \mathrm{~kg}^{-1}\right)$. The blood glucose levels were measured at 0,30,60, 120 and $180 \mathrm{~min}$ post-glucose treatment using Accu-Chek Active (Accu-Chek, Mannheim, Germany)in a drop of blood from the tail. The glucose concentration data were used to compare glucose tolerance in the three groups.

Induction of type $\mathbf{2}$ diabetes: The rats were fasted $12 \mathrm{~h}$ before the streptozotocin injection. A single dose of STZ (45 $\mathrm{mg} \mathrm{kg}^{-1}$ b.wt.), freshly dissolved in $0.05 \mathrm{M}$ citrate buffer $(\mathrm{pH} 4.5)$, was injected through intra peritoneal (i.p) route. Streptozotocin (STZ) was purchased from Sigma-Aldrich Chemical Co. (St. Louis, MO, USA). The development of hyperglycemia was affirmed by the increased fasting blood sugar, blood taken from tail vein, on day seven after injection ${ }^{21}$. After overnight fasting blood glucose level were testing in rats and those with blood glucose levels more than $200 \mathrm{mg} \mathrm{dL}^{-1}$ was considered as diabetic. Blood glucose measurement was performed with an Accu-Chek Active (Accu-Chek, Mannheim, Germany).

Preparation of glibenclamide as a standard anti-diabetic drug: Glibenclamide (glyburide; Sigma-Aldrich, St. Louis, MO, USA) as a standard drug was dissolved in DMSO (dimethyl sulfoxide; Sigma-Aldrich, St. Louis, MO, USA) before administered to the rats as an aqueous suspension at a dose of $5 \mathrm{mg} \mathrm{kg}^{-1}$ body weight ${ }^{22}$.

Design of experimental study: Twenty-four rats were divided into four groups, each of six rats. The first group was considered as the normal healthy group. The remained rats were served as diabetic rats. After an overnight fasting, hyperglycaemia and diabetes were induced in eighteen rats by an intra peritoneal injection of a single dose of freshly prepared STZ, diabetic rats given glucose solution (5\%) for $48 \mathrm{~h}$ after STZ injection to prevent hypoglycemia. Diabetic rats were divided into three groups, each of six rats. The first group was control diabetic rats. Rats of group two and three where rats were given oral administration of crude ethanol extract of cumin seeds (CEEC) (200 $\mathrm{mg} \mathrm{kg}^{-1}$ ) or glibenclamide $\left(5 \mathrm{mg} \mathrm{kg}^{-1}\right)$ for three weeks after induction of diabetes. All rats groups were feed on balanced diet all over the study period. During the experiment, body weight and food intake were recorded weekly. After twenty-one days (end of the study) total food intake, body weight gain and feed efficiency ratio (Body weight gain/total food intake) were calculated. Blood samples were collected from all rats after an overnight fast. Plasma were separated from all blood samples and stored at $-20^{\circ} \mathrm{C}$ before further analysis. All animal procedures were performed in accordance with the Ethics Committee of the National Research Centre, Cairo, Egypt and followed the recommendations of the National Institutes of Health Guide for Care and Use of Laboratory Animals (Publication No. 85-23, revised 1985).

Measurement of plasma glucose and insulin levels: Fasting plasma glucose and insulin were determined according to Trinder $^{23}$ and Turkington et al. ${ }^{24}$, respectively.

Determination of plasma lipid profile: Total cholesterol $(\mathrm{T}-\mathrm{Ch})^{25}$, high density lipoprotein cholesterol $(\mathrm{HDL}-\mathrm{Ch})^{26}$, low density lipoprotein cholesterol (LDL-Ch) ${ }^{27}$ and triglycerides $(\mathrm{TG})^{28}$ were determined in all plasma samples. T-Ch/HDL-Ch ratio was calculated as indicator of cardiovascular risk. 
Evaluation of lipid peroxidation, antioxidant status and inflammatory biomarkers: Plasma malondialdehyde (MDA) ${ }^{29}$ was estimated as an indicator of lipid peroxidation. Total antioxidant capacity (TAC) $)^{30}$ and catalase (CAT) $)^{31}$ were determined as indicator of antioxidant status. Plasma tumor necrosis factor- $\alpha$ (TNF- $\alpha)^{32}$ was determined as an inflammatory biomarker.

Determination of liver and kidney functions: The activity of plasma aspartate transaminase (AST) and alanine transaminase $(\mathrm{ALT})^{33}$ were estimated as indicator of liver function. Plasma levels of creatinine ${ }^{34}$ and urea $^{35}$ were determined to study any possible changes in kidney function.

Acute toxicity test: Acute lethal toxicity test of crude ethanol extract of cumin seeds was carried out according to Goodman et $a / .{ }^{36}$. The $24 \mathrm{~h}$ mortality counts among equal sized groups of mice ( 8 animals/group) receiving progressively increasing oral dose levels of the different extracts were recorded.

Statistical analysis: The results of animal experiments were expressed as the Mean \pm SE and they were analyzed statistically using the one-way analysis of variance ANOVA followed by Duncan's test. In all cases $p<0.05$ was used as the criterion of statistical significance.

\section{RESULTS}

Total phenolic content of cumin crude ethanol extract was observed as $23.02 \pm 0.045 \mathrm{mg} \mathrm{GAE} \mathrm{g}^{-1}$ extract, while total flavonoids was $19 \pm 0.132 \mathrm{mg} \mathrm{QE} \mathrm{g}^{-1}$ extract. The results of free radical scavenging activity of CEEC 200 and $1000 \mu \mathrm{g} \mathrm{m}^{-1}$ was 12 and $40 \%$, respectively.

Oral glucose tolerance: Oral glucose tolerance test revealed that both cumin crude ethanol extract and glibenclamide administration to rats significantly reduced glycemic levels after 0.5 and $1 \mathrm{~h}$ from oral glucose (Fig. 1) compared with the control group which given only glucose $\left(1 \mathrm{~g} \mathrm{~kg}^{-1}\right)$.

Acute toxicity of cumin crude ethanol extract: The acute lethal toxicity test revealed that cumin crude ethanol extract was very safe up to $12 \mathrm{~g} \mathrm{~kg}^{-1}$ mice body weight which corresponds to $93 \mathrm{~g} / 70 \mathrm{~kg}$ man body weight for human when the dose of mice was extrapolated to corresponding estimates in human adopting interspecies dosage conversion scheme ${ }^{37}$. This reflects the highest safety of the cumin crude ethanol extract.

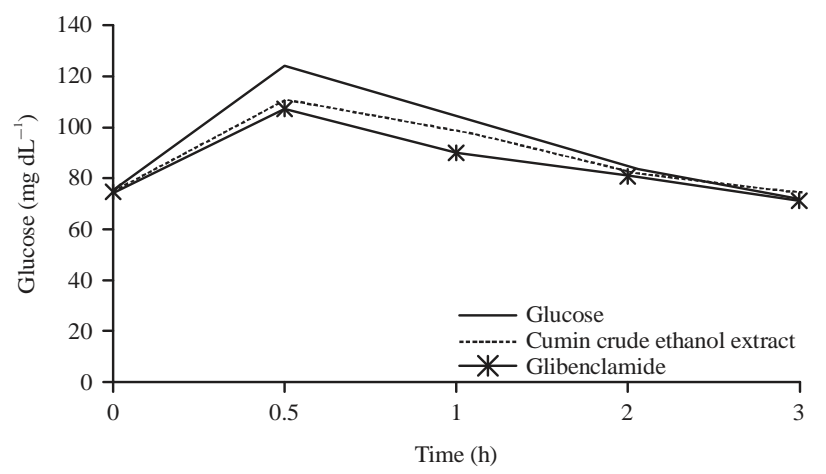

Fig. 1: Glucose tolerance curve of different experimental groups

Values significantly differ from control: ${ }^{*} p<0.001$

Table 1: Plasma glucose and insulin of different experimental groups

\begin{tabular}{lcc}
\hline Groups & Glucose $\left(\mathrm{mg} \mathrm{dL}^{-1}\right)$ & Insulin $\left(\mathrm{mU} \mathrm{L}^{-1}\right)$ \\
\hline Normal control & $68.67 \pm 1.50^{\mathrm{a}}$ & $6.38 \pm 0.23^{\mathrm{c}}$ \\
Diabetic control & $212.83 \pm 2.36^{\mathrm{c}}$ & $3.45 \pm 0.13^{\mathrm{a}}$ \\
Crude ethanol extract of cumin & $131.17 \pm 1.60^{\mathrm{b}}$ & $5.78 \pm 0.13^{\mathrm{b}}$ \\
Glibenclamide & $132.50 \pm 2.045^{\mathrm{b}}$ & $5.90 \pm 0.126^{\mathrm{b}}$ \\
\hline In each column same letters means non-significant difference, different letter \\
means the significance among the tested groups at 0.05 probability
\end{tabular}

Anti-diabetic effect of cumin crude ethanol extract: Diabetes was induced in rats by i.p. injection of STZ $\left(45 \mathrm{mg} \mathrm{kg}^{-1}\right)$. The injection of STZ induces hyperglycemia in rats. Hyperglycemia in the present study was associated with dyslipidemia and oxidative stress as observed by elevation of plasma levels of MDA and reduction of plasma levels of TAC and the reduction of the activity of CAT.

As shown in Table 1, there was significant increase in the blood glucose level of all the diabetic groups, compared to the normal control group. Oral administration of cumin seeds crude ethanol extract or glibenclamide to diabetic rats significantly and progressively restored toward normal. Cumin seeds crude ethanol extract and glibenclamide reduced plasma glucose levels by 38.34 and $37.73 \%$, respectively compared with diabetic control. Diabetic rats showed significant reduction of plasma insulin compared with normal control. Diabetic rats given daily oral dose of glibenclamide or cumin seeds ethanol crude extract observe significant elevation of insulin level compared with diabetic control but still lower than normal control.

Plasma lipid profile of normal and diabetic rats groups was shown in Table 2. Diabetic rats showed significant increase in plasma total cholesterol, triglycerides and LDL-Ch; with a concomitant significant decrease in plasma HDL-Ch levels. However, in comparison with the diabetic control group, the diabetic groups given oral administration of cumin seeds crude ethanol extract and glibenclamide showed 
Table 2: Plasma lipid profile of different experimental groups

\begin{tabular}{|c|c|c|c|c|c|}
\hline Groups & $\mathrm{T}-\mathrm{Ch}\left(\mathrm{mg} \mathrm{dL}^{-1}\right)$ & TG $\left(\mathrm{mg} \mathrm{dL}^{-1}\right)$ & $\mathrm{HDL}-\mathrm{Ch}\left(\mathrm{mg} \mathrm{dL}^{-1}\right)$ & LDL-Ch $\left(\mathrm{mg} \mathrm{dL}^{-1}\right)$ & $\mathrm{T}-\mathrm{Ch} / \mathrm{HDL}-\mathrm{Ch}$ \\
\hline Normal control & $77.3 \pm 1.23^{\mathrm{a}}$ & $80.5 \pm 1.48^{\mathrm{a}}$ & $40.0 \pm 0.58^{c}$ & $19.2 \pm 0.79^{\mathrm{a}}$ & $1.9 \pm 0.04^{\mathrm{a}}$ \\
\hline Diabetic control & $108.3 \pm 1.76^{c}$ & $103.0 \pm 2.25^{c}$ & $28.7 \pm 0.61^{\mathrm{a}}$ & $25.8 \pm 0.60^{\mathrm{b}}$ & $3.8 \pm 0.07^{c}$ \\
\hline Crude ethanol extract of cumin & $88.0 \pm 1.39^{b}$ & $89.0 \pm 1.09^{b}$ & $37.5 \pm 0.96^{b}$ & $20.5 \pm 0.76^{a}$ & $2.4 \pm 0.07^{b}$ \\
\hline Glibenclamide & $89.8 \pm 0.946^{\mathrm{b}}$ & $90.0 \pm 1.483^{b}$ & $35.8 \pm 1.301^{\mathrm{b}}$ & $20.8 \pm 0.543^{b}$ & $2.5 \pm 0.096^{b}$ \\
\hline
\end{tabular}

In each column same letters means non-significant difference, different letter means the significance among the tested groups at 0.05 probability

Table 3: Plasma malondialdehyde, total antioxidant capacity, catalase and tumor necrosis factor- $\alpha$ of different experimental groups

\begin{tabular}{lcccc}
\hline Groups & $\mathrm{MDA}\left(\mathrm{nmol} \mathrm{mL} \mathrm{m}^{-1}\right)$ & $\mathrm{TAC}\left(\mathrm{mM} \mathrm{L}^{-1}\right)$ & $\mathrm{CAT}\left(\mathrm{UL} \mathrm{L}^{-1}\right)$ & \\
\hline Normal control & $8.3 \pm 0.49^{\mathrm{a}}$ & $1.80 \pm 0.06^{\mathrm{c}}$ & $413.3 \pm 6.01^{\mathrm{c}}$ & $13.7 \pm 0.41^{\mathrm{a}}$ \\
Diabetic control & $17.3 \pm 0.55^{\mathrm{c}}$ & $1.00 \pm 0.05^{\mathrm{a}}$ & $197.5 \pm 4.96^{\mathrm{a}}$ & \\
Crude ethanol extract of cumin & $13.8 \pm 0.48^{\mathrm{b}}$ & $1.50 \pm 0.04^{\mathrm{b}}$ & $380.8 \pm 5.83^{\mathrm{b}}$ & \\
Glibenclamide & $13.7 \pm 0.422^{\mathrm{b}}$ & $1.50 \pm 0.045^{\mathrm{b}}$ & $381.3 \pm 5.288^{\mathrm{b}}$ & $20.8 \pm 0.60^{\mathrm{b}}$ \\
\hline
\end{tabular}

MDA: Malondialdehyde, TAC:Total antioxidant capacity, CAT: Catalase, TNF- $\alpha$ : Tumor necrosis factor- $\alpha$. In each column same letters means non-significant difference, different letter means the significance among the tested groups at 0.05 probability

Table 4: Liver and kidney function of different experimental groups

\begin{tabular}{|c|c|c|c|c|}
\hline Groups & ALT $\left(I U L^{-1}\right)$ & AST $\left(I U L^{-1}\right)$ & Urea $\left(\mathrm{mg} \mathrm{dL}^{-1}\right)$ & Creatinine $\left(\mathrm{mg} \mathrm{dL}^{-1}\right)$ \\
\hline Normal control & $33.83 \pm 0.60^{\mathrm{a}}$ & $48.50 \pm 0.76^{a}$ & $27.50 \pm 0.88^{\mathrm{a}}$ & $0.660 \pm 0.02^{\mathrm{a}}$ \\
\hline Diabetic control & $34.33 \pm 0.67^{\mathrm{a}}$ & $49.00 \pm 0.58^{\mathrm{a}}$ & $32.67 \pm 0.61^{\mathrm{b}}$ & $0.910 \pm 0.03^{b}$ \\
\hline Crude ethanol extract of cumin & $34.17 \pm 0.70^{\mathrm{a}}$ & $48.16 \pm 1.05^{\mathrm{a}}$ & $27.83 \pm 0.54^{a}$ & $0.690 \pm 0.02^{\mathrm{a}}$ \\
\hline Glibenclamide & $34.50 \pm 0.764^{\mathrm{a}}$ & $48.30 \pm 1.498^{\mathrm{a}}$ & $28.20 \pm 0.601^{\mathrm{a}}$ & $0.697 \pm 0.028^{a}$ \\
\hline
\end{tabular}

ALT: Alanine transaminase, AST: Aspartate transaminase. In each column same letters means non-significant difference, different letter means the significance among the tested groups at 0.05 probability

Table 5: Nutritional parameters of different experimental groups

\begin{tabular}{|c|c|c|c|c|c|}
\hline Groups & Initial body weight (g) & Final body weight (g) & Body weight gain (g) & Total food intake $(\mathrm{g})$ & Feed efficiency ratio \\
\hline Normal control & $137.8 \pm 2.82^{\mathrm{a}}$ & $178.50 \pm 2.09^{\mathrm{b}}$ & $40.67 \pm 2.03^{c}$ & $237.67 \pm 2.86^{c}$ & $0.170 \pm 0.007^{c}$ \\
\hline Diabetic control & $138.0 \pm 2.72^{\mathrm{a}}$ & $161.50 \pm 2.93^{\mathrm{a}}$ & $23.50 \pm 0.50^{\mathrm{a}}$ & $207.50 \pm 2.22^{\mathrm{a}}$ & $0.110 \pm 0.002^{\mathrm{a}}$ \\
\hline Crude ethanol extract of cumin & $137.8 \pm 2.18^{a}$ & $172.17 \pm 1.30^{\mathrm{b}}$ & $34.33 \pm 1.74^{\mathrm{b}}$ & $223.33 \pm 3.76^{b}$ & $0.150 \pm 0.006^{b}$ \\
\hline Glibenclamide & $137.8 \pm 1.58^{\mathrm{a}}$ & $169.20 \pm 3.03^{\mathrm{a}}$ & $31.30 \pm 2.552^{\mathrm{a}}$ & $224.80 \pm 3.197^{\mathrm{a}}$ & $0.139 \pm 0.011^{\mathrm{a}}$ \\
\hline
\end{tabular}

In each column same letters means non-significant difference, different letter means the significance among the tested groups at 0.05 probability

significant reduction in plasma levels of total cholesterol, triglycerides and LDL-Ch; which combined by significant increase in HDL-Ch. Crude ethanol extract of cumin seeds showed more effective improving in the changes of plasma lipid profile than glibenclamide.

The levels of plasma MDA as indicator of lipid peroxidation (Table 3 ) was significantly elevated in diabetic rats compared with normal rats. The highest elevation was observed in the diabetic control. This elevation was reduced in diabetic rats given oral administration of cumin seeds crude ethanol extract or glibenclamide. Antioxidant status of the various experimental groups was studied through evaluation of plasma levels of total antioxidant capacity (TAC) and the activity of plasma catalase (CAT) (Table 3). Plasma TAC and the activity of CAT were significantly lower in diabetic rats compared with normal rats. Oral administration of diabetic rats with cumin extract or glibenclamide elevate TAC and CAT significantly compared with diabetic control but still lower than normal control. Plasma TNF- $\alpha$ as inflammatory marker increased significantly in diabetic rats compared with normal rats and this increment was reduced significantly in rats given oral administration of cumin extract or glibenclamide.
Liver and kidney function of different experimental groups were shown in Table 4. Liver function of all the studied groups showed non-significant changes as shown by the determination of the activity of AST and ALT. Plasma urea and creatinine as indicator of kidney function showed significant elevation in diabetic rats compared with normal rats. Oral administration of cumin seeds crude ethanol extract or glibenclamide improve the elevation in kidney function as observed in the reduction of plasma levels of urea and creatinine.

The changes in body weights, total food intake and feed efficiency ratio of the various rats groups were presented in Table 5. Diabetic control rats were the lowest group had body weight gain compared with all the studied groups, while normal control rats showed the highest elevation in body weight gain. Diabetic rats groups given oral administration of crude ethanol extract of cumin seeds and glibenclamide showed medium elevation in body weight gain. Also diabetic control showed the significant reduction in feed efficiency ratio compared with all the studied groups. 


\section{DISCUSSION}

Diabetes mellitus (DM) was induced in rats by i.p injection of STZ, which is cytotoxic to pancreatic beta-cells through production of free radicals and involving with the cellular metabolic oxidative mechanisms ${ }^{38}$. DM is a complex disease, which alterations in metabolic and inflammatory markers including disorder in the metabolism of glucose and lipid metabolism abnormalities ${ }^{39}$. DM is characterized by a high risk of adverse cardiovascular and renal outcomes ${ }^{1}$. In the present study cumin crude ethanol extract was used as natural source for anti-diabetic agent.

In the present study Cumin seeds were extracted by ethanol for preparation of crude ethanol extract. Crude ethanol extract contains large amount of phenolic compounds, as found in the present study, which previously possess a wide range of physiological properties, such as antioxidant, anti-microbial, anti-inflammatory, anti-cancer, hypolipidemic, anti-diabetic $\cdots .$. etc ${ }^{40,41}$. Cumin seeds contain safranal, which shows different pharmacological effects like antioxidant, anti-inflammatory and anticancer ${ }^{42}$.

In the present study crude ethanol extract of cumin seeds showed highly antioxidant in vitro through free radical scavenging activity in the DPPH method. The present results are in agreement with the results of Kim et al. ${ }^{43}$. In the present research crude ethanol extract of cumin seeds decrease glucose absorption in normal rats through reduction of the hyperglycemic peak in oral glucose tolerance test performed in normal rats this results is in agreement with the results of Roman-Ramos et al.44, who found that cumin seeds reduced glucose tolerance in normal rabbits.

Also the studied extract possesses anti-diabetic effect in diabetic rats through reduction of plasma glucose levels and elevation of insulin in plasma. The antioxidant activity and anti-diabetic effect may be due to the presence of total phenolic and flavonoids compounds as observed in the present study. Administration of cumin crude ethanol extract to diabetic rats improved plasma lipid profile, oxidative stress status and inflammation. Cumin seeds crude ethanol extract reduced the elevation in plasma urea level as one of the kidney function. Crude ethanol extract of cumin seeds attenuate the reduction of body weight in diabetic rats as observed by the elevation of body weight gain.

Hypoinsulinemia in diabetic rats observed in the present study may be due to reduction of protein synthesis in all tissues as reported by Gray and Cooper ${ }^{45}$. Dyslipidemia presence in diabetic rats in the present study is a common feature of DM due to insulin deficiency ${ }^{46}$. The alteration in lipid profile in diabetic rats in the present study is in agreement with the results of Zhang et al/.47. Dyslipidemia is one of the major risk factors for cardiovascular disease in $\mathrm{DM}^{48}$. Abnormalities in lipid metabolism due to increased free fatty acid release from insulin-resistant fat cells leads to alterations in plasma lipid profile in DM. Normally insulin modulates lipid metabolism by activating lipoprotein lipase, which hydrolyze triglycerides to release fatty acids and glycerol. Fatty acids are oxidized for fuel or reesterified for storage in the body tissues. In the case of insulin deficiency and/or resistance in DM lipoprotein lipase is inactivated, which lead to hypertriglyceridemia ${ }^{48}$. The increment in LDL levels enhances the deposition of cholesterol in the arteries and aorta and consequently the development of coronary heart disease in diabetic patients. LDL helps to transport cholesterol from liver to body tissues ${ }^{49}$. HDL helps to transport endogenous cholesterol and cholesteryl esters from other body tissues to the liver and steroidogenic tissues where they are metabolized and excreted. So HDL is regarded as a beneficial lipoprotein that prevents cholesterol deposition in the system, thereby preventing atherosclerosis ${ }^{50}$. Thus the elevation in plasma insulin is the main cause for the observed amelioration in plasma lipid profile.

Oxidative stress presence in the diabetic rats in the present research as observed by elevation of lipid peroxidation (MDA) and reduction of TAC and CAT activity is in agreement with the results of Shalaby and Shanab ${ }^{51}$. Lipid peroxidation is an oxidative deterioration of polyunsaturated fatty acids, involving reactive oxygen species and transition metal ions, which yield diverse cytotoxic products such as MDA. MDA can disrupt the function of the membrane, increase tissue permeability and inactivate membrane-bound receptors and enzymes ${ }^{52}$. The increment in MDA levels may induce oxidative damage in liver, which is responsible of lipid metabolism, so elevate lipid profile in diabetic rats ${ }^{53}$. As a result of elevation of lipid peroxidation and free radical TAC and CAT activity were reduced.

In the present study TNF- $\alpha$ as inflammatory marker elevates in diabetic rats, this elevation may be attributed to the elevation of oxidative stress and reactive oxygen species, which observed in the present research. Chronic low-grade inflammation is one of the most important complications in diabetes ${ }^{54}$. Hyperglycemia elevates reactive oxygen species, which lead to stimulation and initiate immune response through production of inflammatory cytokines such as TNF- $\alpha^{54,55}$.

It was reported previously that cumin seeds powder $\left(2 \mathrm{~g} \mathrm{~kg}^{-1}\right)$ reduced glucose levels in hyperglycaemic rabbits ${ }^{56}$. Cumin seeds powder (1.25\%) improved the reduction in body weight observed in diabetic rats, which accompanied by 
lowered in plasma urea ${ }^{57}$. Patil et al.58 reported that cumin seeds contain cuminaldehyde and cuminol. Both cuminaldehyde and cuminol showed potent insulinotropic effects. The insulinotropic action of both components was glucose-dependent and due to the closure of ATP-sensitive $\mathrm{K}$ ( $\mathrm{K}^{+}$-ATP) channel and the increase in intracellular $\mathrm{Ca}^{2+}$ concentration. The authors concluded that cumin seeds were able to reduced glucose without causing hypoglycaemia or beta-cell burn out. Different extracts of cumin seeds possessed many nutraceutical properties such as anti-allergic, antioxidant and hypoglycemic ${ }^{59}$.

\section{CONCLUSION}

In this study crude ethanol extract cumin seeds possess antioxidant and anti-diabetic effects. This extract showed complete safety. Crude ethanol extract cumin seeds may be used as an alternative treatment for diabetes mellitus in diabetic patients.

\section{SIGNIFICANCE STATEMENT}

This study confirmed that crude ethanol extract of cumin seeds as an alternative treatment for diabetes. The extract contains high content of phenolic compounds and flavonoids which possess antioxidant in vitro in DPPH method. It's so important to use this rich source of phenolic compounds and flavonoids in preparation of alternative treatment to enhance human health and reduce the spread of non-communicable disease such as type- 2 diabetes and its side effects to human health.

\section{REFERENCES}

1. Mancia, G. and G. Grassi, 2018. Blood pressure targets in type 2 diabetes. Evidence against or in favour of an aggressive approach. Diabetologia, 61:517-525.

2. Dain, A., G. Repossi, G.T. Diaz-Gerevini, J. Vanamala, U.N. Das and A.R. Eynard, 2016. Long Chain Polyunsaturated Fatty Acids (LCPUFAs) and Nordihydroguaiaretic Acid (NDGA) modulate metabolic and inflammatory markers in a spontaneous type 2 diabetes mellitus model (Stillman Salgado rats). Lipids Health Dis., Vol. 15. 10.1186/s12944-0160363-8.

3. Hongyan, Z., Z. Jian, Z. Lei, M. Jianhui, S. Yongning and Z. Yuwu, 2015. Characteristics of blood glucose excursions in type 2 diabetes mellitus patients with three different traditional Chinese medicine syndromes. J. Tradit. Chinese. Med., 35: 537-545.
4. American Diabetes Association, 2015. Standards of medical care in diabetes-2015 abridged for primary care providers. Clin. Diabetes, 33: 97-111.

5. Onyeji, C.O., S.I. Igbinoba and G. Olayiwola, 2017. Therapeutic potentials and cytochrome P450-mediated interactions involving herbal products indicated for diabetes mellitus. Drug Metab. Lett., 11: 74-85.

6. Roozbeh, N., L. Darvish and F. Abdi, 2017. Hypoglycemic effects of Acacia nilotica in type II diabetes: A research proposal. BMC Res. Notes, Vol. 10. 10.1186/s13104-0172646-1.

7. Prabhakar, P.K. and M. Doble, 2011. Mechanism of action of natural products used in the treatment of diabetes mellitus. Chin. J. Integr. Med., 17: 563-574.

8. Gachkara, L., D. Yadegaria, M.B. Rezaeib, M. Taghizadehc, S.A. Astaneh and I. Rasooli, 2007. Chemical and biological characteristics of Cuminum cyminum and Rosmarinus officinalis essential oils. Food Chem., 102: 898-904.

9. El-Ghorab, A.H., M. Nauman, F.M. Anjum, S. Hussain and M. Nadeem, 2010. A comparative study on chemical composition and antioxidant activity of ginger (Zingiber officinale) and cumin (Cuminum cyminum). J. Agric. Food Chem., 58: 8231-8237.

10. Jagtap, A.G. and P.B. Patil, 2010. Antihyperglycemic activity and inhibition of advanced glycation end product formation by Cuminum cyminum in streptozotocin induced diabetic rats. Food Chem. Toxicol., 48: 2030-2036.

11. Prakash, E. and D.K. Gupta, 2014. Cytotoxic activity of ethanolic extract of Cuminum cyminum Linn against seven human cancer cell line. Univ. J. Agric. Res., 2: 27-30.

12. Pandey, S., M.K. Patel, A. Mishra and B. Jha, 2015. Physio-biochemical composition and untargeted metabolomics of cumin (Cuminum cyminum L.) make it promising functional food and help in mitigating salinity stress. PLos One, Vol. 10. 10.1371/journal.pone.0144469.

13. Mostafa, D.M., A.A. Kassem, M.H. Asfour, S.Y. Al Okbi, D.A. Mohamed and T.E.S. Hamed, 2015. Transdermal cumin essential oil nanoemulsions with potent antioxidant and hepatoprotective activities: In-vitro and in-vivo evaluation. J. Mol. Liq., 212: 6-15.

14. Briggs, G.M. and M.A. Williams, 1963. A new mineral mixture for experimental rat diets and evaluation of other mineral mixtures. Fed. Proc., 22: 261-266.

15. Morcos, S.R., 1967. The effect of the protein value of the diet on the neurological manifestations produced in rats by

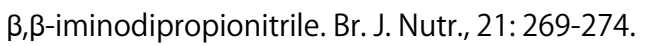

16. Singleton, V.L., R. Orthofer and R.M. Lamuela-Raventos, 1999. Analysis of total phenols and other oxidation substrates and antioxidants by means of Folin-Ciocalteu reagent. Methods Enzymol., 299: 152-178. 
17. Chang, C.C., M.H. Yang, H.M. Wen and J.C. Chern, 2002. Estimation of total flavonoid content in propolis by two complementary colorimetric methods. J. Food Drug Anal., 10: 178-182.

18. Teke, G.N., P.K. Lunga, H.K. Wabo, J.R. Kuiate and G. Vilarem et al., 2011. Antimicrobial and antioxidant properties of methanol extract, fractions and compounds from the stem bark of Entada abyssinica Stend ex A. Satabie. BMC Complem. Altern. Med., Vol. 11. 10.1186/14726882-11-57.

19. Rebolleda, S., M.T. Sanz, J.M. Benito, S. Beltran, I. Escudero and M.L.G. San-Jose, 2015. Formulation and characterisation of wheat bran oil-in-water nanoemulsions. Food Chem., 167: 16-23.

20. Tatar, M., D. Qujeq, F. Feizi, H. Parsian and A.S. Faraji et al., 2012. Effects of Teucrium polium aerial parts extract on oral glucose tolerance tests and pancreas histopathology in streptozocin-induced diabetic rats. Int. J. Mol. Cell. Med., 1: 44-49.

21. Su, H.C., L.M. Hung and J.K. Chen, 2006. Resveratrol, a red wine antioxidant, possesses an insulin-like effect in streptozotocin-induced diabetic rats. Am. J. Physiol. Endocrinol. Metab., 290: E1339-E1346.

22. Masih, M., T. Banerjee, B. Banerjee and A. Pal, 2011. Antidiabetic activity of Acalypha indica Linn. on normal and alloxan induced diabetic rats. Int. J. Pharm. Pharmaceut. Sci., 3: 51-54.

23. Trinder, P., 1969. Determination of glucose in blood using glucose oxidase with an alternative oxygen acceptor. Ann. Clin. Biochem., 6: 24-27.

24. Turkington, R.W., A. Estkowski and M. Link, 1982. Secretion of insulin or connecting peptide a predictor of insulin dependence of obese diabetics. Arch. Intern. Med., 142: 1102-1105.

25. Watson, D., 1960. A simple method for the determination of serum cholesterol. Clin. Chim. Acta, 5: 637-643.

26. Burstein, M., H.R. Scholnick and R. Morfin, 1970. Rapid method for the isolation of lipoproteins from human serum by precipitation with polyanions. J. Lipid Res., 11: 583-595.

27. Schriewer, H., U. Kohnert and G. Assmann, 1984. Determination of LDL cholesterol and LDL apolipoprotein B following precipitation of VLDL in blood serum with phosphotungstic acid/MgCl . J. Clin. Chem. Clin. Biochem., 22: 35-40.

28. Mcgraw, R.E., D.E. Dunn and H.G. Biggs, 1979. Manual and continuous-flow colorimetry of triacylglycerols by a fully enzymatic method. Clin. Chem., 25: 273-278.

29. Satoh, K., 1978. Serum lipid peroxide in cerebrovascular disorders determined by a new colorimetric method. Clinica Chimica Acta, 90: 37-43.
30. Koracevic, D., G. Koracevic, V. Djordjevic, S. Andrejevic and V. Cosic, 2001. Method for the measurement of antioxidant activity in human fluids. J. Clin. Pathol., 54: 356-361.

31. Aebi, H., 1984. Catalase in vitro. Methods Enzymol., 105: 121-126.

32. Stepaniak, J.A., K.E. Gould, D. Sun and R.A. Swanborg, 1995. A comparative study of experimental autoimmune encephalomyelitis in Lewis and DA rats. J. Immunol., 155: 2762-2769.

33. Reitman, S. and S. Frankel, 1957. Colorimetric methods for aspartate and alanine aminotransferases. Am. J. Clin. Pathol., 28: 55-60.

34. Houot, O., 1985. Interpretation of Clinical Laboratory Tests. In: Reference Values and their Biological Variation, Siest, G., J. Henny, F. Schiele and D.S. Young (Eds.). Biomedical Publications, USA., pp: 220-234.

35. Fawcett, J.K. and J.E. Scott, 1960. A rapid and precise method for the determination of urea. J. Clin. Pathol., 13: 156-159.

36. Goodman, A.G., L.S. Goodman and A. Gilman, 1980. Principles of Toxicology. In: The Pharmacological Basis of Therapeutics, Goodman, A.G. and A. Gilman (Eds.). 6th Edn., Macmillan, New York, pp: 1602-1615.

37. Paget, G.E. and J.M. Barnes, 1964. Evaluation of Drug Activities. In: Pharmacometrics, Lawrence, D.R. and A.L. Bacharach (Eds.). Vol. 1, Academic Press, New York, pp: 160-167.

38. Papaccio, G., F.A. Pisanti, M.V. Latronico, E. Ammendola and M. Galdieri, 2000. Multiple low-dose and single high-dose treatments with streptozotocin do not generate nitric oxide. J. Cell Biochem., 77: 82-91.

39. Orio, F., L. Vuolo, S. Palomba, G. Lombardi and A. Colao, 2008. Metabolic and cardiovascular consequences of polycystic ovary syndrome. Minerva Ginecol., 60: 39-51.

40. Heim, K.E., A.R. Tagliaferro and D.J. Bobilya, 2002. Flavonoid antioxidants: Chemistry, metabolism and structure-activity relationships. J. Nutr. Biochem., 13: 572-584.

41. Manach, C., A. Mazur and A. Scalbert, 2005. Polyphenols and prevention of cardiovascular diseases. Curr. Opin. Lipidol., 16: 77-84.

42. Rezaee, R. and H. Hosseinzadeh, 2013. Safranal: From an aromatic natural product to a rewarding pharmacological agent. Iran. J. Basic Med. Sci., 16: 12-15.

43. Kim, I.S., M.R. Yang, O.H. Lee and S.N. Kang, 2011. Antioxidant activities of hot water extracts from various spices. Int. J. Mol. Sci., 12: 4120-4131.

44. Roman-Ramos, R., J.L. Flores-Saenz and F.J. Alarcon-Aguilar, 1995. Anti-hyperglycemic effect of some edible plants. J. Ethnopharmacol., 48: 25-32. 
45. Gray, S.P. and M.E. Cooper, 2011. Diabetic nephropathy in 2010: Alleviating the burden of diabetic nephropathy. Nat. Rev. Nephrol., 7: 71-73.

46. Chahil, T.J. and H.N. Ginsberg, 2006. Diabetic syslipidemia. Endocrinol. Metab. Clin. N. Am., 35: 491-510.

47. Zhang, W., J. Zhao, J. Wang, X. Pang, X. Zhuang, X. Zhu and W. Qu, 2010. Hypoglycemic effect of aqueous extract of seabuckthorn (Hippophae rhamnoides L.) seed residues in streptozotocin-induced diabetic rats. Phytother. Res., 24: 228-232.

48. Chehade, J.M., M. Gladysz and A.D. Mooradian, 2013. Dyslipidemia in type 2 diabetes: Prevalence, pathophysiology and management. Drugs, 73: 327-339.

49. Pedersen, T.R., 2001. Pro and con: Low-density lipoprotein cholesterol lowering is and will be the key to the future of lipid management. Am. J. Cardiol., 87: 8-12.

50. Xu, Y., Z. He and G.L. King, 2005. Introduction of hyperglycemia and dyslipidemia in the pathogenesis of diabetic vascular complications. Curr. Diabet. Rep., 5: 91-97.

51. Shalaby, E. A. and S.M.M. Shanab, 2013. Antioxidant compounds, assays of determination and mode of action. Afr. J. Pharm. Pharmacol., 7: 528-539.

52. Rahman, I., 2003. Oxidative stress, Chromatin remodeling and gene transcription in inflammation and chronic lung diseases. J. Biochem. Mol. Boiol., 36: 95-109.
53. Annadurai, T., A.R. Muralidharan, T. Joseph, M.J. Hsu, P.A. Thomas and P. Geraldine, 2012. Antihyperglycemic and antioxidant effects of a flavanone, naringenin, in streptozotocin-nicotinamide-induced experimental diabetic rats. J. Physiol. Biochem., 68: 307-318.

54. Moubarz, G., M.A. Embaby, N.M. Doleib and M.M. Taha, 2016. Effect of dietary antioxidant supplementation (Cuminum cyminum) on bacterial susceptibility of diabetes-induced rats. Central-Eur. J. Immunol., 41: 132-137.

55. Brownlee, M., 2005. The pathobiology of diabetic complications: A unifying mechanism. Diabetes, 54: 1615-1625.

56. Jain, S.C., M. Purohit and R. Jain, 1992. Pharmacological evaluation of Cuminum cyminum. Fitoterapia, 63: 291-294.

57. Willatgamuwa, S.A., K. Platel, G. Saraswathi and K. Srinivasan, 1998. Antidiabetic influence of dietary cumin seeds (Cuminum cyminum) in streptozotocin induced diabetic rats. Nutr. Res., 18: 131-142.

58. Patil, S.B., S.S. Takalikar, M.M. Joglekar, V.S. Haldavnekar and A.U. Arvindekar, 2013. Insulinotropic and $\beta$-cell protective action of cuminaldehyde, cuminol and an inhibitor isolated from Cuminum cyminumin streptozotocin-induced diabetic rats. Br. J. Nutr., 110: 1434-1443.

59. Sowbhagya, H.B., 2013. Chemistry, technology and nutraceutical functions of cumin (Cuminum cyminum $\mathrm{L}$ ): An overview. Crit. Rev. Food Sci. Nutr., 53: 1-10. 